\title{
ORGANIZATIONAL PREDICTORS OF EXTERNAL LEADER BEHAVIORS IN SELF-MANAGED WORK TEAMS
}

\author{
David F. Elloy, Gonzaga University
}

dx.doi.org/10.18374/CBR-1-2.5

\begin{abstract}
As American organizations have experienced more intense competition in the global economy self- managed work teams has become more important to both researchers and practitioners in recent years (Guzzo and Dickson, 1996; Langfred, 2000). In order to remain competitive and profitable the use of work teams has grown considerably in the US and it has become an important management innovation and new organizational design over the past decades with up to half of all employees soon to be working in a team environment (Manz and Sims, 1993; Stewart and Manz, 1995). In addition , research studies have also found that hat work teams have been important contributors to the effectiveness of organizations (Dunphy and Bryant, 1996). The use of self-managing teams, where employees are organized into work teams and allowed to make a variety of decisions which previously only management made are now seen to be increasing in a variety of organizations in the US (Druskat and Wheeler, 2003).
\end{abstract}

Keywords: 